\title{
RELAÇÃO CUSTO-BENEFÍCIO NA ESTRATÉGIA CAMPONESA DE PRODUÇÃO DE SEMENTES PRÓPRIAS
}

\author{
the cost-benefit relationship in peasant agriculture \\ strategy for the production of own seeds
}

\author{
Eliane Tomiasi Paulino ${ }^{1}$ \\ Josué Maldonado Ferreira ${ }^{2}$ \\ Rosângela Maria Pinto Moreira ${ }^{3}$ \\ aaAaa
}

\begin{abstract}
Resumo
A artificialização na agricultura encerra um circuito em que os desequilíbrios ambientais a ela associados são resolvidos com intervenções que os aprofundam cada vez mais, o que impõe a busca pela sustentabilidade, expressão polissêmica da qual também tem se valido os agentes hegemônicos desse paradigma produtivo para mantê-lo, como forma de assegurar a acumulação de capital. Apesar de essa lógica atender às necessidades da agricultura capitalista, que tem a seu favor a escala e a mobilidade produtiva, o mesmo não pode ser dito da agricultura camponesa, que tem nas pequenas frações de terra um patrimônio a ser preservado como condição para sua própria reprodução. E sobre os resultados de um projeto dessa natureza, em curso no Norte do Paraná, que trata esse trabalho.
\end{abstract}

Palavras-chave: Territorialidades camponesas, Produção de sementes próprias, Melhoramento genético participativo, Aumento da renda, Empoderamento.

\begin{abstract}
Agriculture artificialization closes a circle in which associated environmental imbalances are resolved with interventions that most of the times deepens the problems even more, thus demanding a search for sustainability, a polysemic expression of which hegemonic agents of this productive paradigm have also used to maintain it as a way to guarantee capital accumulation. Even though this logic has met the needs of capitalist agriculture, which has in its favor production scale and mobility, the same cannot be said about peasant farming, which has in their small fractions of land an asset to be preserved as a condition for their own reproduction. It is for this fraction of farmers that conventional technical solutions have been unsatisfactory, as, for instance, in seeds, which moved from mankind heritage to a commodity. This work discusses the results of a project of this nature, developed in a course in Northern Paraná.
\end{abstract}

Key words: Peasant territoriality, Own seeds production, Participative genetic improvement, Income increase, Empowerment.

\begin{abstract}
Resumen
En el contexto de la artificialización de la agricultura los desequilibrios ambientales están siendo tratados con intervenciones que solamente tornan ellos más agudos, el que impone la búsqueda de la sustentabilidad, un término polisémico que los agentes hegemónicos del paradigma productivo actual también usan para asegurar la acumulación de capital. A pesar de la artificialización atender las necesidades de la agricultura capitalista, que tiene a su favor la gran escala y la movilidad productiva, lo mismo no puede decirse de la agricultura campesina, que disfruta solo de pequeñas fracciones de tierra, nada más que todo su património, lo cual tiene que conservase como una condición para su propia reproducción. Son los resultados de una experiencia desarrollada por campesinos del norte de Paraná que este trabajo presenta.
\end{abstract}

Palabras clave: Territorialidades campesinas, Producción de semillas propias, Fitomejoramiento participativo, Aumento de la renta, Empoderamiento.

(1) Bolsista Produtividade do CNPq, Prof ${ }^{a} \operatorname{Dr}^{\mathrm{a}}$ da Universidade Estadual de Londrina - Rodovia Celso Garcia Cid, km 380 , CEP: 86055-900 - Londrina (PR), Brasil, Tel./Fax.: (+55 43) 33714246 / 33714216 - eliane.tomiasi@uel.br

(2) Prof. Dr. da Universidade Estadual de Londrina - Rodovia Celso Garcia Cid, km 380, CEP: 86055-900 - Londrina (PR), Brasil, Tel./Fax.: (+ 55 43) 33714417 / 33714207 - josuemf@uel.br

(3) (2) Prof ${ }^{\mathrm{a}}$. Dr ${ }^{\mathrm{a}}$. da Universidade Estadual de Londrina - Rodovia Celso Garcia Cid, km 380, CEP: 86055-900 - Londrina (PR), Brasil, Tel./Fax.: (+ 55 43) 33714000 / 33714207 - rosang@uel.br

\section{aaAaa}

Revista da ANPEGE, v. 8, n. 9, p. 61-72, jan./jul. 2012.

ISSN 1679-768 X @ 2003, Associação Nacional de Pesquisa e Pós-Graduação em Geografia. Todos os direitos reservados. 


\section{INTRODUÇÃO}

A agricultura que, durante milênios, sustentou-se em sistemas simples de produção, com elevada incorporação de trabalho e baixa, senão nula, adição de componentes externos às regiões de cultivo, alcançou um desenvolvimento em que, a despeito dos parcos rendimentos para os atuais padrões de produtividade, incontestável eficiência do ponto de vista da adaptabilidade às mais variadas condições edafoclimáticas que caracterizam o ambiente no planeta. Isso se deu graças ao concurso de técnicas de melhoramento genético, tão antigas como a agricultura e a comporem fazer parte das estratégias de sobrevivência humana antes mesmo do surgimento das civilizações da antiguidade.

Ao legado desse caráter dinâmico nas práticas agrícolas, indissociável das condições materiais de existência fundantes das tradições e valores dos povos, é que se pode atribuir parte da variabilidade genética verificada entre as espécies comestíveis. Por sua vez, a importância dessa variabilidade somente pode ser aferida correlacionado-a à capacidade de serem asseguradas condições regulares de provimento de alimentos mesmo em situações de acidez ou baixa fertilidade dos solos, estresse ou excesso hídrico, altas e baixas temperaturas, latitudes e altitudes, entre outros.

Contudo, os padrões de artificialização que emergiram da Revolução Industrial e foram sendo paulatinamente incorporados na agricultura cada vez mais colocam em risco o equilíbrio instituído nesses termos. De acordo com a FAO/ONU (2011), há atualmente cerca de um bilhão de pessoas em situação de privação crônica de comida, o que mostra que embora a agricultura convencional tenha demonstrado uma inquestionável capacidade de incremento na produção de alimentos e matérias primas de origem vegetal, ela não tem sido capaz de resolver o principal problema a ela afeto: a fome. Aliás, é exatamente ao padrão agrícola disseminado nos últimos 50 anos que se pode atribuir, em parte, essa situação, pois a modernização técnica implicou em êxodo rural intenso, gerando um padrão de urbanização tanto mais caótico quanto a velocidade de sua disseminação, com cidades que se alastraram porque tomadas como destino possível para os expulsos da terra, que aí encontraram, em regra, o lugar para a inclusão precária, sendo a fome uma de suas expressões. Muitos dos que permaneceram não tiveram destino melhor, não por acaso a maior quantidade de famintos do planeta paradoxalmente vive no campo, em situação de deficiente acesso à terra e à ocupação capaz de proporcionar renda. A isso soma-se o passivo ambiental que esse paradigma técnico está legando ao planeta, sob a forma de envenenamento das águas superficiais e subterrâneas, assoreamento dos corpos hídricos, desflorestamento, erosão genética, entre outros.

São os limites desse modelo produtivo que colocam à ciência o desafio de produzir conhecimentos que atendam aos segmentos da sociedade privados das soluções técnicas por ela própria gestadas, seja porque essas estão de tal modo aprisionadas no circuito da propriedade intelectual que seu custo é proibitivo para a maioria dos agricultores, seja porque ao custo monetário de sua incorporação soma-se um custo socioambiental que muitos não estão dispostos a perpetuar.

Este contexto motivou a realização de um trabalho a associar pesquisa e extensão universitárias, tendo como sujeitos pequenos agricultores. O recorte geográfico é o Norte do Paraná, precisamente a região de Londrina onde são empreendidas e estudadas, desde 2006, estratégias de produção e conservação de sementes de milho, associada ao melhoramento genético das variedades cultivadas.

\section{LIMITES DA MODERNIZAÇÃO TÉCNICA DA AGRICULTURA}

Em um cenário marcado pelo mito do agronegócio, da concentração de capitais e da monopolização dos negócios vinculados ao consumo produtivo, economicamente falando a agricultura camponesa comparece, não raro, como um setor ineficiente, incapaz de contribuir com a riqueza nacional. Isso se revela, em parte, na própria produção acadêmica e mais explicitamente em princípios que regem a gestão territorial, a exemplo das políticas públicas de fomento à agricultura. Uma evidência disso é a denominação utilizada pelo Estado brasileiro para diferenciar a produção capitalista e a produção camponesa, à qual subjaz a divisão de todos os recursos destinados a esse 
setor de atividade: designa-se a primeira de agricultura comercial e a segunda de agricultura familiar que, implicitamente, quer designar um outro circuito que não o das trocas mercantis, e esse só poderia ser o da subsistência, porque supostamente ela não o estaria transcendendo.

Não se trata, assim, de uma diferenciação restrita à nomenclatura, antes reflete uma concepção política de lógica produtiva para o campo, e o aporte de recursos o confirmará. Considerando-se apenas o período em que as políticas de fomento à agricultura familiar entraram de fato na agenda do Estado brasileiro, fato ocorrido a partir de 2003, em nenhum plano safra subseqüente o montante de recursos foi superior a $15 \%$ do que pode desfrutar a agricultura empresarial, eufemisticamente denominada de agricultura comercial, como se a primeira não o fosse. $\mathrm{O}$ recurso disponibilizado para a safra 2011/2012 foi de, respectivamente, 16 e 107,2 bilhões de reais.

A distinção teórica entre agricultura comercial e não comercial, ao fim, justificaria tão assimétrica distribuição de recursos, embora os resultados em termos econômicos entre ambas explicitem a distorção existente, já que de acordo com o último levantamento censitário realizado pelo Instituto Brasileiro de Geografia e Estatística (IBGE, 2009), a agricultura familiar contribuiu com $37,8 \%$ da produção, em valor, da agropecuária nacional. Na região Sul, onde as políticas de povoamento originais favoreceram a agricultura familiar, a participação atingiu 51,9\%, ou seja, superou a denominada agricultura comercial, mesmo dispondo de apenas $31,5 \%$ da área agricultável e de subvenção ínfima.

Mais do que evidenciar a distorção das políticas públicas, em termos de fomento à produção agrícola, tais dados exprimem as potencialidades da produção camponesa, que para florescer em plenitude necessitam de estudos científicos que as identifiquem e as explicitem para o conjunto da sociedade. Trata-se, pois do desafio de desconstruir o mito da superioridade produtiva associada à produção tecnificada e de grande escala, que não surgiu do acaso, mas dos pactos hegemônicos que se valem da partilha assimétrica dos recursos públicos e propagam uma circularidade desfavorável à produção de pequena escala, porque pautados em uma racionalidade técnica que não a contempla.

Não por acaso, as inovações nesse campo estão voltadas, em regra, para a produção de grande escala. Mesmo considerando-se seus limites em termos ambientais, como se verá adiante, pode-se afirmar que os grandes proprietários tem se beneficiado economicamente dos conhecimentos advindos de diversas pesquisas que se traduzem em novas tecnologias para a produção no campo, entretanto essa escala de produção não admite soluções pautadas na compatibilização com os ciclos da natureza, daí o desdém para com as práticas sustentáveis para além do plano do discurso.

O mesmo não pode ser dito quando se trata da agricultura camponesa, progressivamente acuada pelos custos, variável que se apresenta em relação inversamente proporcional à escala da produção, em parte devido à renúncia ao princípio da adequação em favor do princípio de adaptação que as tecnologias agrícolas impõem.

Ao trazer para o foco da pesquisa esses sujeitos, busca-se romper com o usual encarceramento do conhecimento científico que lhes dá origem e que, por definição, tende ao alheamento dos grupos sociais que mais necessitam dele, pela sua própria condição social e econômica. A aproximação possível, nesse caso, se deu por meio do estabelecimento de parcerias com comunidades camponesas que podem se valer, na prática, de conhecimentos científicos traduzidos em procedimentos técnicos passíveis de serem incorporados nas práticas produtivas cotidianas, como é o caso da produção de sementes próprias para utilização em suas propriedades.

É sobre os resultados dessa experiência que esse artigo se detém, começando pela análise das possibilidades de se compatibilizar a proposta de atender a uma demanda específica da agricultura, o provimento de sementes, que tem no mercado o seu mediador por excelência, em vista do diferencial dos cultivares comercializados em termos de produtividade.

Se do ponto de vista quantitativo essa mediação parece ser capaz de dar as respostas que a humanidade necessita em termos de provisão de alimentos, algumas questões depõem contra a sua sustentabilidade. Em primeiro lugar, deve-se mencionar que paralelamente ao aumento progressivo da produtividade na agricultura, para a qual concorreu a tríade sementes selecionadas, insumos quí- 
micos e máquinas, tem aumentado também a horda de famintos. É exatamente a população agrícola e rural que, em sua maioria, a compõe, particularmente aquelas que vivem na África, Ásia e América Latina, continentes em que as mudanças técnicas fundadas na quimificação e na mecanização já completaram meio século, sem qualquer indício de eliminação do quadro de pobreza no campo.

Em segundo lugar, o ônus para a elevação da produtividade nos termos técnicos correntes tem sido demasiadamente alto, dado o passivo ambiental ora disseminado na agricultura. Nas regiões onde está a maioria dos camponeses nas condições citadas predominam condições edafoclimáticas completamente diversas daquelas em que foram gestadas as soluções técnicas artificiais para o campo, de modo que é necessário analisar os benefícios e os impactos da mecanização a partir de um critério geográfico: se nas regiões temperadas esse procedimento tornou-se um aliado para o aquecimento das camadas inferiores do solo, em vista da menor disponibilidade de luz solar ao longo do ano, nas regiões equatoriais e tropicais esse problema não se coloca, de modo que as práticas correlatas tendem a trazer mais malefícios do que benefícios.

De acordo com Sidiras e Pavam (1985), a utilização de grades e arados mecânicos expõe o solo à decomposição acelerada da matéria orgânica, ao aumento da acidez, à perda da capacidade de fixação dos nutrientes, à redução da atividade biológica, ao aumento da densidade e consequente redução da umidade. Em regiões de precipitações pluviométricas acentuadas, a tais impactos associa-se a erosão. De acordo com Griebeler, Carvalho e Matos (2000), em condições climáticas e morfológicas similares às da região Sul do Brasil, a perda média estimada de solo fértil em áreas intensivamente mecanizadas é de 15 a 20 toneladas por hectare ao ano. Semelhantes apontamentos podem ser encontrados em Fregonezi e Espindola (2008), que se debruçaram sobre o comportamento da fertilidade dos solos em diferentes situações no Norte do Paraná, região em que o projeto de sementes está sendo desenvolvido, e concluíram que em condições convencionais de mecanização, as perdas proporcionais de fertilidade natural são maiores do que em condições de manejo com plantio direto.

Em suma, à mecanização deve-se associar não apenas ganhos, como tem sido feito, sendo imperioso contabilizar as perdas econômicas, dada a necessidade de aumentar progressivamente a adição de adubos químicos no solo para garantir os índices de fertilidade compatíveis com as exigências agrícolas, cálculo que já começa a ocupar especialistas de universidades e institutos públicos de pesquisa, a exemplo de Marques e Pazzianoto (2004).

Além disso, há um impacto incomensurável no sistema hídrico como um todo, em vista do assoreamento dos cursos d'água. Se a deposição de sedimentos nos corpos hídricos provoca a redução do volume de água disponível, outro processo ocorre paralelamente, comprometendo a sua qualidade. Trata-se da eutrofização, atualmente incidente em diferentes níveis em todas as regiões de agricultura intensiva, pois os compostos dos fertilizantes são carreados para os cursos hídricos, favorecendo a proliferação de algas em níveis que desequilibram o ecossistema aquático, o que ao fim resulta em diminuição da quantidade de oxigênio disponível aos peixes e mesmo a liberação de toxinas que tornam a água imprópria para consumo.

No Brasil, o problema adquire especial gravidade quando se considera os índices de consumo proporcional à área agrícola. Debruçando-se sobre os dados divulgados pela International Fertilizer Industry (IFI), Teixeira (2011) conclui que apesar de o Brasil comparecer como o quarto maior consumidor de fertilizantes do planeta, perdendo apenas para a China, Índia e Estados Unidos, em termos de área proporcional é o campeão. Isso porque a área cultivada com cereais na China é 4.4 vezes superior à do Brasil, a da Índia é de 4.8 vezes e, por fim, a dos Estados Unidos é 3 vezes maior.

À utilização excessiva de fertilizantes e seus impactos para a qualidade das águas deve ser associado o descontrole no consumo de agrotóxicos, que igualmente pode ser considerado um fator de inquietação no Brasil que, desde 2008, alçou à condição de maior consumidor de veneno agrícola do planeta, a despeito de área cultivada incomparavelmente menor que a dos países citados. Um fator agravante ainda deve ser considerado, já que no país existe uma distribuição desigual na utilização do insumo. De acordo com Jardim, Andrade e Queiroz (2009), a região Sul é responsável 
por $31,2 \%$ do consumo de agrotóxicos no Brasil, contudo sua participação territorial é de apenas $6,8 \%$ na superfície total do país. No estado do Paraná, cuja área corresponde a apenas $2,3 \%$ do território nacional, utiliza-se cerca de $16,2 \%$ do veneno agrícola, sendo as culturas da soja e milho as que proporcionalmente apresentam maior demanda pelo insumo.

Tal situação potencializa uma série de impactos, contudo tem sido regra a não contabilização indireta dos custos implícitos, e a intoxicação humana parece ser um dos mais perversos. De acordo com o Instituto Brasileiro de Geografia e Estatística (IBGE), em 2004 a relação entre quantidade utilizada nas lavouras e população absoluta resultou numa taxa per capita de $2,8 \mathrm{~kg}$ por habitante, quantidade sete vezes superior à média mundial. Além disso, a composição dos agrotóxicos de uso comum no país é outro agravante, pois muitas substâncias e princípios ativos que já foram banidos em vários países, dado o comprovado malefício à saúde humana e ao ambiente, seguem sendo usados, seja em virtude da entrada ilegal dos produtos no país ou até mesmo em virtude de fragilidades legais das quais tem se valido as indústrias para assegurar esse mercado privilegiado que é o Brasil.

Sabe-se que a indústria de insumos agrícolas é uma das mais concentradas entre os setores industriais e o caso dos agrotóxicos é a melhor evidência disso: de acordo com Silva (2011), 90\% do mercado brasileiro é controlado por treze empresas, sendo que $65 \%$ desse mercado é compartilhado por apenas seis delas. Tal situação é uma evidência do monopólio existente no setor, o que favorece relações assimétricas em seu favor, no que concerne aos agricultores, consumidores finais e mesmo às instâncias de regulação, em face de lacunas jurídicas existentes. Apesar da Lei 7.802, em vigor desde 1989, que pró́be qualquer operação envolvendo agrotóxicos que tenham características mutagênicas, teratogênicas, carcinogênicas, entre outros efeitos nocivos, uma vez obtido o registro pela indústria, ele é definitivo, não havendo imperativos legais que obriguem à sua renovação periódica mediante novos estudos de compatibilidade ambiental ou com a saúde humana, ao contrário de medicamentos e demais substâncias que impõem como marco regulatório o princípio da precaução.

Por isso, a suspensão do registro de agrotóxicos é muito rara no país e, em regra, envolve batalhas jurídicas. Até porque a competência para fazê-lo está loteada entre três instâncias públicas, a Agência Nacional de Vigilância Sanitária (ANVISA), que os analisa a luz de possíveis impactos à saúde pública, o Instituto Brasileiro do Meio Ambiente e dos Recursos Naturais Renováveis (IBAMA), cuja preocupação são os possíveis impactos ao meio ambiente e, por fim, o Ministério da Agricultura (MAPA), que atenta para a eficácia agronômica do produto.

É essa estrutura que favorece a desregulamentação em curso, posto que o Ministério da Agricultura é uma instância de hierarquia máxima na esfera administrativa do Estado e sua razão de ser é o fomento à produção e aos dividendos monetários, o qual tem se rendido à estratégia de disseminação de soluções imediatas para a agricultura. Eis a razão pela qual vem sendo editadas uma série de portarias e aditivos à Lei 7.802, tornando-a mais branda em relação ao texto original, ao mesmo tempo em que aumentam as possibilidades de se conceder ao MAPA a atribuição de regular o setor, como se não houvesse implicações do ponto de vista ambiental e humano, prerrogativas de avaliação a cargo do IBAMA e da ANVISA, respectivamente.

Esse é o contexto político que marca a vulnerabilização da cláusula da reavaliação, possível de ser solicitada por ambos os órgãos quando há evidências de que o produto é nocivo. Em 2008 a ANVISA iniciou um processo de reavaliação de 14 ingredientes utilizados em fórmulas de agrotóxicos, após confluência de evidências científicas de sua nocividade. Desses, apenas seis foram concluídos, cinco dos quais graças a ações judiciais ganhas contra as indústrias, que tentam impedi-las tanto quanto possível (SILVA, 2011). As demais estão suspensas, sob júdice e, enquanto isso perdurar, a fabricação e distribuição se dará sem entraves.

A essa combinação de riscos soma-se o da erosão genética, porque as práticas fundadas na mecanização e na quimificação tem sido acompanhadas de uma seleção de variedades aptas a responder melhor a essas formas de manejo. Com isso, a perda de biodiversidade igualmente se constitui em 
ameaça, a começar pela própria dinâmica dos ecossistemas que, quanto mais simplificados, mais vulneráveis à ação de organismos concorrentes.

Outro problema deriva do monopólio sobre a agricultura, expresso na redução da variedade de vegetais cultivados, porque esse é um imperativo para o controle mencionado. O milho, o cereal com o qual se tem trabalhado na experiência de produção de sementes próprias, foi um dos cereais que mais mobilizaram a indústria desde o advento dos híbridos, a qual passou a atuar no circuito das sementes articulado ao dos insumos, em regime de monopólio cada vez mais acentuado. De acordo com Pinheiro (2008), apenas seis cultivares foram responsáveis por $71 \%$ da área plantada com milho no Brasil naquele ano.

Em suma, são impasses como esses que servem como contraponto para se avaliar a sustentabilidade da agricultura tecnicamente modernizada em longo prazo. Isso impõe a necessidade de se buscar alternativas de produção que demonstrem maior compatibilidade ambiental, para não falar social, posto que ela também é excludente e esse ciclo ainda não se esgotou. A redução de variedades está associada à simplificação das operações de manejo, e os transgênicos são o melhor exemplo, e tudo isso culmina na redução da demanda por força de trabalho na atividade, daí a advertência de Teubal (2008) dos riscos da agricultura sem agricultores. Ao prescindir do labor humano, em favor das máquinas, e do saber, protegido pelas patentes, a atividade torna-se cada vez objeto de controle, submetido aos cálculos do lucro, que não combinam com sua atribuição maior: o provimento de comida suficiente e saudável a todo ser humano.

É isso que justifica o esforço de construir juntamente com os camponeses estratégias de fortalecimento da condição de agricultores em sentido estrito, o que supõe buscar alternativas para o circuito de saturações hoje característico, em que as mudanças técnicas exigem intervenções exógenas para a produção fluir. A cada intervenção dessa natureza, novas saturações se avizinham, de modo que novas técnicas são requeridas para a superação das dificuldades técnicas daí oriundas. $\mathrm{Na}$ prática, trata-se de dificuldades reveladas pelo descompasso entre as artificialidades criadas e os ciclos da natureza, que possuem dinâmica própria, não sendo passíveis de desativação pelos parâmetros de controlabilidade que emanam do paradigma técnico.

Se para os grandes produtores não há como fugir disso, até porque é por meio da simplificação das operações que se consegue produzir dentro da lógica industrial, daí a interminável corrida pelo aumento da escala, da qual irá depender os lucros, os pequenos produtores não tem como manter os padrões de rentabilidade que esse circuito impõe. Isso porque eles não dispõem de terra suficiente para a utilização plena do aparato produtivo que é concebido para funcionar em larga escala.

Por outro lago, Ploeg (2008) vislumbra no que denomina de artesanalidade as possibilidades de os camponeses tirarem proveito daquilo que é mais abundante em suas unidades de produção: força de trabalho e saber fazer. Embora não se trate de dádiva, porque isso resulta de uma condição inerente à unidade de produção familiar e é exclusiva dela, a produção camponesa é portadora de uma lógica que permite uma aproximação estratégica com o mercado, reduzindo ao máximo o consumo de itens regidos pelo princípio da taxa média de lucro.

Nesses termos, a artesanalidade se revela, segundo o autor, na capacidade de reduzir sempre que possível a dependência a insumos externos à unidade para garantir a produção, de um lado, e da fuga dos mercados controlados pelas grandes corporações, que são os mercados globalizados, os quais se configuram como os principais pontos de estrangulamento para a produção camponesa, a exemplo do mercado de sementes. É justamente nesse ponto que o projeto de produção de sementes próprias consegue atuar, como se poderá depreender na sequência.

\section{A RELAÇÃO CUSTO-BENEFÍCIO NA PRODUÇÃO DE SEMENTES PRÓPRIAS}

O trabalho em questão foi implantado em 2006, em quatro comunidades do município de Londrina e, posteriormente, outras acabaram aderindo, algumas do próprio município e outras de Cambé, Tamarana, Ortigueira, Florestópolis e Assaí. Desde então, os dados vem sendo coletados, de modo que para efeito dessa análise o limite é a safra de verão do ano de 2010, colhida no início 
de 2011, e os 14 locais onde implantou-se a experiência.

As etapas a serem destacadas podem ser definidas linearmente apenas para os respectivos locais em que é implementado o trabalho, já que a cada adesão tudo recomeça, num ciclo que ainda não se esgotou na região. Uma vez identificada a comunidade e constituído o grupo interessado em realizar o trabalho, os pesquisadores realizam no próprio local os encontros de capacitação para o embasamento teórico e prático, o planejamento das atividades e a discussão das metodologias participativas de trabalho. Nessa fase, que antecede a semeadura, os agricultores são preparados para atuar em todas as atividades de instalação, condução e avaliação do cultivo experimental, denominado ensaio de competição. É nessa fase que os camponeses começarão a colocar em prática o aporte técnico que lhes permitirá lançar-se na experiência de produzir campos de sementes próprias, em que se dará o processo de melhoramento genético a cada safra. (FERREIRA et al, 2010).

O ensaio de competição consiste na semeadura de um campo com 21 cultivares de milho, sendo 5 variedades crioulas, 7 variedades sintéticas, 3 compostos crioulos, 2 variedades comerciais, 2 variedades em desenvolvimento e, por fim, 2 híbridos simples, obedecendo-se o princípio de serem referência na região, em termos de desempenho (BARROS; MOREIRA; FERREIRA, 2010).

O objetivo desse ensaio é identificar o desempenho de cada cultivar nas condições específicas do lugar, e que podem variar devido ao microclima, ao solo, à topografia e às condições usuais de manejo. Por isso, são incluídas variedades de domínio público, eventualmente algumas já utilizadas por eles próprios, até os híbridos comerciais considerados os mais produtivos na região, que constituir-se-ão em parâmetros para os camponeses julgarem se a relação custo-benefício será assegurada com a renúncia à esse material de ponta, pelos custos implícitos à sua aquisição e cultivo.

A segunda etapa, após um rigoroso controle de desempenho quanto à germinação, ciclo vegetativo, suscetibilidade a doenças, quantidade de massa verde, entre outros, consiste na escolha pelas próprias comunidades daquelas que desejam submeter ao melhoramento genético, o que de antemão exclui os híbridos comerciais, que não podem ser reproduzidos como semente.

O melhoramento genético tem início com a implantação dos campos de sementes a cada safra, em lotes isolados, por vezes em áreas comuns, onde mais de uma família trabalha e, ocasionalmente, em propriedades individuais. É a diversidade própria da lógica camponesa de produzir que determina as escolhas dos agricultores.

Aí começa a produção de sementes próprias, que passará ano a ano por ciclos de melhoramento genético. Os agricultores escolhem o material mais conveniente segundo as necessidades de cada propriedade. Alguns escolhem as mais produtivas, em termos de grãos, porque precisam alimentar aves e animais e também desejam destinar parte da colheita ao mercado. Outros escolhem as que tem mais massa verde, nos casos em que a atividade principal da propriedade é a criação de médios e grandes animais e o milho será utilizado na forma de silagem, como complemento alimentar. Há ainda aqueles que optam por cultivares com ciclo vegetativo mais longo, porque necessitam prolongar a disponibilidade de milho verde e assim por diante.

Todos os experimentos são feitos respeitando-se as práticas de cultivo e os níveis de tecnologia usuais em cada comunidade que, em regra, estão baseadas na utilização muito baixa, senão nula de agrotóxicos e alguma utilização de fertilizante, exceto no caso dos agricultores orgânicos, que não utilizam nenhum insumo artificial. Outro aspecto que merece destaque é o fato de serem os próprios agricultores quem definem os locais onde são implantados os experimentos, obviamente obedecendo-se princípios técnicos mínimos, e também como se dará a condução da atividade, se de maneira individual ou comunitariamente.

Os dados utilizados para efeito de análise são os aferidos nos campos de experimentos, pois a partir da produção dos campos de sementes ainda não é possível, com os recursos que a equipe dispõe e considerando a quantidade e diversidade das lavouras cultivadas, fazer o monitoramento preciso dos índices. Optou-se por adotar como parâmetro de comparação os dados de produtividade aferidos pelo órgão público responsável pela agricultura, a Secretaria de Agricultura e Abastecimento do Estado do Paraná (SEAB, 2011), que acompanha sistematicamente a produção agrícola segundo 
as diferentes culturas, as diferentes safras e as diferentes regionalizações, definidas segundo critérios de zoneamento agroclimático. Nesse caso, os dados referem-se à regional de Londrina, que abrange todos os municípios onde o trabalho está disseminado.

Para estabelecer parâmetros de comparação, optamos por apresentar, para cada safra, os dados do experimento que apresentou a maior produtividade, considerando-se o material mais produtivo, bem como a sua posição no experimento segundo parâmetros estatísticos em que se classifica por blocos os materiais cuja produtividade é considerada similar. Esses parâmetros são cientificamente definidos segundo critérios estatísticos específicos para os estudos em genética de milho.

$\mathrm{Na}$ safra 2006/2007, a produtividade média aferida pela SEAB para o município de Londrina foi de $7.140 \mathrm{~kg}$. Nessa safra foram realizados três ensaios de competição, respectivamente no Bairro Oitenta Alqueires, no Bairro Guairacá e no Assentamento Pó de Serra, todos localizados no município de Londrina. Nesse experimento, os maiores índices de produtividade foram alcançados no Assentamento Pó de Serra, sendo que o melhor resultado foi de um híbrido comercial, que produziu o correspondente a $9.320 \mathrm{~kg}$ por hectare. No segundo estrato, o material mais produtivo foi a variedade SINT UEL 0409, desenvolvida por pesquisadores do projeto, que produziu $8.120 \mathrm{~kg}$ por hectare, $13,7 \%$ a mais que a média alcançada no município de Londrina nessa safra.

Quanto ao híbrido de melhor desempenho, seu rendimento foi $14,8 \%$ superior ao SINT UEL 0409, posição que se revelou com certa regularidade, pois em todos os experimentos os híbridos ficaram no primeiro estrato de produtividade, eventualmente trocando de posições entre si, o que não poderia ser diferente, dado o aparato técnico-científico-comercial envolvido em sua produção. Não por acaso, estão protegidos pelo direito de patentes, sendo esse um dos ingredientes dos altos preços das sementes comerciais. No segundo estrato estão as variedades, que igualmente trocaram de posições entre si, destacando-se algumas sintéticas e algumas crioulas, como se poderá constatar. Por isso, a diversidade nas escolhas dos camponeses para seus campos de sementes, que tenderam para aquelas com desempenho considerado excepcional para as condições de manejo, guardadas as necessidades das respectivas unidades de produção.

Na safra de verão 2007/2008, o dado referência utilizado da SEAB não é o do município, mas o da região de Londrina, que consiste na produtividade média alcançada por 19 municípios que compõem a regional, e que englobam os municípios onde houve experimentos. Nessa safra foram realizados dois experimentos, um no município de Tamarana, contíguo ao município de Londrina e outro no Município de Florestópolis, cerca de $66 \mathrm{~km}$ ao Norte deste município, respectivamente no Assentamento Libertação Camponesa e no Assentamento Florestan Fernandes.

O melhor desempenho foi observado no Assentamento Florestan Fernandes, sendo que o híbrido comercial produziu $9.150 \mathrm{~kg}$ por hectare, enquanto para as variedades o melhor resultado foi de $7.140 \mathrm{~kg}$, referente ao SINT UEL 1309, produtividade que não diferiu estatisticamente das médias aferidas pela SEAB, que foi de $7.196 \mathrm{~kg}$ por hectare. Nesse aspecto, é necessário ressaltar que a produção de milho na região, em termos territoriais, é predominantemente realizada com os híbridos de ponta e com a adição de adubo e agrotóxicos em volumes recomendados pelo fabricante, o que permite inferir que os resultados com as variedades são absolutamente competitivos, porque os camponeses não desfrutam de condições semelhantes aos produtores de escala, que determinam os índices médios na região.

Em relação à safra de verão 2008/2009, mais três ensaios de competição foram realizados, dessa vez no Assentamento do Banco da Terra Fazenda Akolá e Comunidade Doze Tribos, ambos no município de Londrina, bem como no Assentamento Libertação Camponesa, no município de Ortigueira, no qual obteve-se a maior produtividade, respectivamente $8.500 \mathrm{~kg}$ por hectare para um híbrido comercial e $6.930 \mathrm{~kg}$ por hectare para uma variedade crioula, o composto 2 .

Nessa safra a média aferida pela SEAB para a região de Londrina foi de $4.744 \mathrm{~kg}$ por hectare. Essa foi uma das safras em que observou-se uma quebra representativa, em virtude da escassez pluviométrica ao longo do ciclo vegetativo do milho. Esse fato impõe a necessidade de se analisar tais resultados sob dois prismas: o primeiro é o desempenho da variedade mais produtiva onde 
se realizou os experimentos, com produtividade média $46,1 \%$ superior ao aferido pela SEAB. O segundo diz respeito à resposta das variedades em situações de estresse hídrico, pois das dezenove cultivadas naquela safra, apenas duas tiveram desempenho inferior à média aferida pela SEAB.

É precisamente essa situação que constitui um diferencial para os camponeses que produzem sementes próprias. Primeiro, em situações de quebras de safra, que são recorrentes na lavoura do milho, as perdas monetárias são pequenas, por não ter havido compra de sementes e investimento baixo em fertilizantes e agrotóxicos. Segundo, a rusticidade das variedades garante que se tenha colheitas, mesmo menores em relação aos anos padrão. Por outro lado, em tais situações os que são dependentes das sementes comerciais e o pacote tecnológico correspondente sofrem impactos monetários significativos. Quando esses produtores dispõem de uma reserva monetária é possível assimilar tais impactos, e isso é uma realidade apenas para aos grandes que, por força de escala, nos anos bons conseguem acumular. Para os camponeses, essa situação pode representar um desequilíbrio irrecuperável, porque é a venda da colheita que lhes permitirá saldar as dívidas contraídas para a produção daquele ano.

Enquanto na safra de verão as condições climáticas desfavoráveis à cultura do milho são ocasionais, na safra de inverno elas são recorrentes, razão pela qual ela é denominada de safrinha. Nessas condições, as variedades se revelaram altamente competitivas. A título de exemplo, destacamos os dados obtidos em 2010, no ensaio de competição realizado na Fazenda Escola da UEL. O melhor híbrido comercial produziu $5.770 \mathrm{~kg}$ por hectare enquanto a variedade SINT UEL 2309 produziu $5.530 \mathrm{~kg}$ por hectare, uma produção $36,1 \%$ superior à média aferida pela SEAB nessa safra em Londrina, que foi de $4.240 \mathrm{~kg}$ por hectare.

Em relação à safra 2009/2010, foi realizado um ensaio de competição em sistema orgânico de manejo, envolvendo produtores orgânicos da APOL do Município de Assaí. Nessa safra, o melhor resultado alcançado por híbrido comercial foi de $10.040 \mathrm{~kg}$ por hectare, ao passo que um milho crioulo, da variedade Caiano, foi o que apresentou maior produtividade, mais precisamente 7.900 $\mathrm{kg}$ por hectare. Cabe salientar que esse resultado foi superior à média aferida pela $\mathrm{SEAB}$, que foi de $7.707 \mathrm{~kg}$ por hectare, dentro das condições técnicas já citadas.

É isso que comprova a viabilidade da produção de sementes próprias, desde que conduzidas com critérios científicos, a exemplo do que tem sido feito no projeto, cujos resultados tenderão a acréscimos de produtividade a cada safra, observando-se os procedimentos de melhoramento genético.

Para além da produtividade em si, faz-se necessário explicitar outra variável, o custo das sementes próprias em relação às comerciais. O exercício a seguir leva em consideração o custo aferido em um campo de sementes do município de Londrina na safra de verão colhida em 2011 e o preço dos híbridos comerciais praticados na Cocamar, principal cooperativa da região de Londrina na atualidade. Considerando a dimensão de um campo de sementes, com $2.000 \mathrm{~m} 2$, em que não utilizou-se qualquer insumo e foram colhidos $1.600 \mathrm{~kg}$ de milho, o custo estimado foi de $\mathrm{R} \$$ 230,00, assim distribuído:

Tabela 1- Custo da produção de sementes próprias

\begin{tabular}{l|c|c|c|}
\hline Procedimento & Unidade referência & Quantidade & \multicolumn{1}{c}{ Valor (R\$) } \\
\hline Preparo de solo & Animal/dia & 01 & 50,00 \\
\hline Plantio & Homem/dia & 01 & 30,00 \\
\hline Capina & Homem/dia & 02 & 60,00 \\
\hline Colheita & Homem/dia & 01 & 30,00 \\
\hline Preparo das amostras & Homem/dia & 02 & 60,00 \\
\hline
\end{tabular}

Considerando que para semear um hectare são necessários de 12 a $20 \mathrm{~kg}$, dependendo do tamanho da semente e da peneira que foi utilizada para a seleção, tomamos como referência o gasto médio de $16 \mathrm{~kg}$ por hectare. Sendo assim, esse campo produziu semente suficiente para cultivar 100 hectares de milho, o que obviamente não será utilizado pelo agricultor em questão, cujo sítio tem apenas seis hectares. Isso significa que a parte ociosa poderá ser trocada com outros agriculto- 
res da região, o que aliás começa a ser uma prática entre os camponeses que já a produzem, o que significa um incremento extra de renda, posto que o valor referência nas trocas é $\mathrm{R} \$ 2,50$, quando o custo para produzi-las é de $\mathrm{R} \$ 0,143$. Obviamente trata-se de um custo referencial, pois a força de trabalho é inerente à propriedade, e dificilmente haveria chance de remuneração similar em outra atividade interna, porque as possibilidades de ocupação da força produtiva estão sendo utilizadas.

Para além dos fatores já elencados, como autonomia em relação a esse bem essencial para o agricultor, a semente de qualidade e sob seu controle, esse dado deve ser analisado à luz de outros parâmetros. Na região onde estão sendo produzidas as sementes, os benefícios transcendem as propriedades envolvidas, posto que a vizinhança está tendo acesso a ela mediante mecanismos de troca cruzada (PAULINO, 2006), prática comum entre os camponeses para fugir à mediação do mercado e, assim, reduzir os custos de sua atividade, mecanismo igualmente identificado por Ploeg (2008).

Sendo assim, para esse agricultor que produziu sua própria semente, o custo por hectare será de $\mathrm{R} \$ 2,28$. Já para o agricultor que a adquirir, o custo médio será de $\mathrm{R} \$ 40,00$. Caso tais agricultores viessem a comprar os híbridos utilizados nos ensaios de competição, o valor seria de R $\$ 256,00$ e $\mathrm{R} \$ 271,00$, respectivamente no período referência de tomada dos preços, julho de 2011.

Considerando que para os camponeses a disponibilidade de dinheiro é um impedimento por vezes severo para acesso até mesmo às sementes que necessitam cultivar, esses dados falam por si. Enfim, nessa região do Brasil a aproximação entre o saber científico e o fazer camponês tem resultado na produção de sementes competitivas, de baixíssimo custo, gerando independência em dois sentidos: primeiro pela disponibilidade permanente na propriedade e, segundo, pelo domínio das técnicas de produzí-las e melhorá-las a cada safra.

\section{CONSIDERAÇÕES FINAIS}

A possibilidade de produzir sementes próprias, desde que competitivas, permite aumentar a renda da propriedade, primeiro porque as sementes comerciais são caras e, segundo, porque elas são produzidas a partir de um ambiente padrão, que é o da monocultura capitalista, cujas condições de manejo e de acesso ao mercado são absolutamente diferentes daquelas dos camponeses.

Por outro lado, a incorporação das técnicas de ponta de melhoramento genético pelos próprios camponeses, graças às orientações passadas no acompanhamento regular dos pesquisadores aos campos de sementes significa um empoderamento ímpar. Para além do resultado econômico, a prática de produção de sementes próprias fortalece laços de sociabilidade no interior das comunidades e devolve aos camponeses o que a maior parte deles já havia perdido com o advento da mecanização associada à quimificação: o controle sobre esse patrimônio, dimensões essas que contemplam o princípio da relevância social, o fim último do fazer científico.

Não obstante tais resultados, algumas dificuldades merecem menção, às quais tributa-se mais ao paradigma hegemônico do que propriamente à sua incompatibilidade com a produção camponesa. Consideramos que a mais persistente diz respeito à dificuldade em encontrar camponeses dispostos a se envolver nos experimentos e, posteriormente, dar continuidade ao processo de melhoramento genético de sementes conforme os preceitos técnicos exigidos. Isso tanto é verdadeiro que alguns camponeses não deram prosseguimento ao trabalho, tendo desistido predominantemente após a colheita dos experimentos nos ensaios de competição. Nesses casos, a preferência pela compra de sementes no mercado tem a ver com a comodidade, já que estima-se que cada campo de sementes requer, em média, seis dias/homem de trabalho, mas não só isso, uma vez que muitos dos agricultores que hoje sobrevivem de suas pequenas propriedades dispõem de força de trabalho reduzida, pois os filhos acabaram por se assalariar na cidade e, eventualmente no campo, em vista da renda insuficiente da unidade de produção.

Entre os que passaram à fase seguinte, a da produção do campo de sementes, as desistências não são relevantes e, nos casos registrados, não foram justificadas por possíveis ônus relativos aos cuidados com os campos de semente ou por resultado produtivo considerado insuficiente. 
Em alguns casos, pesou a necessidade de os camponeses partirem para lavouras mais competitivas, já que os preços do milho pagos ao produtor nos últimos anos foram severamente deprimidos. Em outros casos, depôs contra o projeto a redução da força de trabalho disponível, nas ocasiões em que alguns membros da família vincularam-se a trabalhos urbanos, em face da dificuldade de auferir rendimentos monetários na propriedade. Concluímos assim que o projeto é auspicioso nas situações em que o foco é a policultura com agregação de valor, o que a lavoura produzida com sementes próprias oportuniza, já que num mercado concentrado e regulado por práticas monopolísticas, a produção de grãos necessita de escala para garantir renda compatível com as necessidades das famílias e isso os camponeses não tem a seu favor.

Aliás, são esses entraves que levaram a uma desestruturação que hoje é uma realidade no campo brasileiro, a qual afeta o projeto e sobre a qual não se tem possibilidade de intervenção, porque se trata de lacunas estruturais, próprias de um país em que a agricultura camponesa nunca foi prioridade nas políticas públicas e a produção de alimentos jamais foi considerada uma atividade estratégica. Por isso as restrições de renda manifestadas na terra insuficiente, no baixo acesso a ferramentas e maquinários e, principalmente, nos parcos recursos acessados para fomento à produção, são uma barreira contra o projeto, que não sucumbe em vista da existência de agricultores e pesquisadores dispostos a negar a excludente lógica hegemônica em curso no campo e, por extensão, na cidade.

É tempo de acabar com a mentira de que apenas a agricultura promovida pela tecnologia pode salvar a humanidade da inanição. O oposto é verdadeiro. É preciso uma nova forma de balanço econômico que, à medida que soma o que é chamado "produtividade" ou "progresso" na agricultura, também deduza todos os custos: as calamidades humanas, a devastação ambiental, a perda da diversidade biológica na paisagem circundante e, ainda, a mais tremenda perda, a biodiversidade em nossos cultivares. (LUTZEMBERGER, 2001, p. 68).

\section{AGRADECIMENTOS}

Agradecimentos especiais são devidos ao Conselho Nacional de Desenvolvimento Científico e Tecnológico-CNPq, Fundação Araucária e Secretaria de Ciência e Tecnologia do Estado do Paraná bem como ao técnico da Emater de Londrina Paulo Roberto Mrtvy, cujo apoio financeiro e operacional, respectivamente, foram fundamentais para a realização do trabalho.

\section{REFERÊNCIA BIBLIOGRÁFICA}

ANVISA. Agência Nacional de Vigilância Sanitária - Agrotóxicos e toxicologia. Disponível em: <http:// portal.anvisa.gov.br/wps/portal/anvisa/home/agrotoxicotoxicologia>. Acesso em: 19 maio 2011.

BARROS, L. B.; MOREIRA, R. M. P.; FERREIRA, J. M. Phenotypic, additive genetic and environment correlations of maize landraces populations in family farm systems. Scientia Agrícola (USP. Impresso), v. 67, p. 685-691, 2010.

BRASIL. Lei 7.802, de 11 de julho de 1989. Dispõe sobre a pesquisa, a experimentação, a produção, a inspeção e a fiscalização de agrotóxicos, seus componentes e afins, e dá outras providências. Disponível em: $<$ http://www.planalto.gov.br/ccivil_03/leis/17802.htm>. Acesso em: 15 abr. 2011.

FAO - Organização das Nações Unidas para Agricultura e Alimentação. O estado da insegurança alimentar no mundo. Disponível em: <www.fao.org.> Acesso em: 28 jun. 2011.

FERREIRA et al. Avaliação de cultivares de milho crioulo em sistema de baixo nível tecnológico. Acta Scientiarum Agronomy (Online), v. 32, p. 229-233, 2010.

FREGONEZI, G. A. F.; ESPINDOLA, C. R. Perfil de manejo na identificação de modificações químicas do solo decorrentes do uso agrícola. Revista Semina, Ciências Agrárias, Londrina, v. 29, n.3, p. 485-498, jul./set. 2008. Disponível em: <http://www.uel.br/proppg/portal/pages/arquivos/pesquisa/semina/pdf/semina_29_3_19_2.pdf $>$. Acesso em: 13 jul. 2011. 
GRIEBELER, N. P.; CARVALHO, D. F.; MATOS, A. T. Estimativa do custo de implantação de sistema de terraceamento utilizando-se o sistema de informações geográficas: estudo de caso. Revista Brasileira de Engenharia Agrícola e Ambiental, Campina Grande, v. 4, n. 2, 2000. Disponível em: <http://www.scielo. br/scielo.php?pid=S1415-43662000000200029\&script=sci_arttext $>$. Acesso em: 05 jul. 2011.

IBGE. INSTITUTO BRASILEIRO DE GEOGRAFIA E ESTATÍSTICA. Censo Agropecuário 2006: Agricultura Familiar. Rio de Janeiro: IBGE, 2009.

IBGE. Instituto Brasileiro de Geografia e Estatística - Relatório de desenvolvimento sustentável. Disponível em: $<$ http://seriesestatisticas.ibge.gov.br/lista_tema.aspx?op=0\&no=16>. Acesso em: 18 maio 2011.

JARDIM, I. C. S. F.; ANDRADE, J. A.; QUEIROZ, S. C. N. Resíduos de agrotóxicos em alimentos: uma preocupação ambiental global . Química Nova, v. 32, n. 4, p. 996-1012, 2009. Disponível em: <http://www. scielo.br/pdf/qn/v32n4/v32n4a31.pdf>. Acesso em: 05 jul. 2011.

KUHN, T. A estrutura das revoluções científicas. 5. ed. São Paulo: Perspectiva, 1998.

LUTZENBERGER, J. A. O absurdo da agricultura. Estudos Avançados, São Paulo, USP, v. 15, n. 43, p. 61-74, 2001. Disponível em: <http://www.scielo.br/pdf/ea/v15n43/v15n43a07.pdf > Acesso em: 13 jul. 2011.

MARQUES, J. F; PAZZIANOTTO, C. B. Custos econômicos da erosão do solo: estimativa pelo método do custo de reposição de nutrientes. EMBRAPA, Comunicado Técnico n. 23, Jaguariuna, 2004. Disponível em: <http://www.cnpma.embrapa.br/analise_econ/>. Acesso em: 13 jul. 2011.

PAULINO, E. T. Por uma geografia dos camponeses. São Paulo: UNESP, 2006.

PINHEIRO, J. B. et al (Org.). Impactos do melhoramento de plantas no agronegócio. Piracicaba: ESALQ/ USP, 2008.

PLOEG, J. D. V.D. Camponeses e impérios alimentares: lutas por autonomia e sustentabilidade na era da globalização. Porto Alegre: UFRGS, 2008.

SANTOS, M. Por uma outra globalização. São Paulo: Record, 2000.

SEAB. Secretaria de Estado da Agricultura e do Abastecimento. Estimativa de Safra: comparativo de área, produção e produtividade para a cultura de milho. Disponível em: $<$ http://www.seab.pr.gov.br/>. Acesso em: 17 jul. 2011.

SEAB. Secretaria de Estado da Agricultura e do Abastecimento. Manual técnico do subprograma de manejo e conservação do solo. Curitiba: SEAB, 1994.

SIDIRAS, N.; PAVAN, M. A. Influência do sistema de manejo do solo no nível de fertilidade. Revista Brasileira de Ciência do Solo, Campinas, v. 9, n. 3, p. 249-254, 1985.

SILVA, L. R. A luta pela reavaliação de agrotóxicos no Brasil. Revista do Instituto Humanitas da Universidade Unisinos, São Leopoldo, Rio Grande do Sul. Disponível em: $<$ http://www.ihuonline.unisinos.br/ index.php?option=com_content\&view=article\&id=3978\&secao=368> Acesso em: 12 jul. 2011.

TEIXEIRA, G. As Mudanças no Código Florestal: “Alternativa" para a ineficiência produtivista do agronegócio. Disponível em: <http://www.agb.org.br/documentos/Artigo_codigo_produtividade_maio_2011. pdf $>$. Acesso em: 11 jun. 2011.

TEUBAL, M. O campesinato frente à expansão dos agronegócios na América Latina. In: PAULINO, E.T.; FABRINI, J. E. Campesinato e territórios em disputa. São Paulo: Expressão Popular, 2008. p. 139-160.

Trabalho enviado em janeiro de 2012

Trabalho aceito em fevereiro de 2012 